small airways injury (bronchiolitis). The presence of bronchiolitis could not, however, be confirmed as no lung biopsy was performed.

We conclude that acute exposure to high concentrations of anhydrous ammonia gas leads not only to acute respiratory injury but also to long term impairment of respiratory function.

1 Slot MJ. Ammonia burns. Lancet 1938;ii:1356-7.

2 Caplin M. Ammonia gas poisoning. Lancet 1941;ii:95-6.
3 Sobonya R. Fatal anhydrous ammonia inhalation. Hum Pathol 1977;8:293-9.

4 Levy DM, Mathew BD, Thaddens JL, Henderson JW. Ammonia burns of the face and respiratory tract. JAMA 1964;190:873-6.

5 Montague TJ, Macneil AR. Mass ammonia inhalation. Chest 1980;77:496-8.

6 Haddad LM, Winchester JF. Clinical management of poisoning and drug overdose. 2nd ed. Philadelphia: Saunders, 1990:1270.

7 Klaassen CD, Amdur MO, Doull J. Toxicology: the basic science of poisons. New York: Macmillan, 1986:330-57.

8 Kass I, Zamel N, Dobry CA, Holzer M. Bronchiectasis following ammonia burns of the respiratory tract. Chest 1972;62:282-5.

9 Hoeffler HB, Schweppe HI, Greenberg SD. Bronchiectasis following pulmonary ammonia burn. Arch Pathol Lab Med 1982;106:686-7.

\section{Expandable metal stents for tracheal obstruction: permanent or temporary? A cautionary tale}

\author{
C R K Hind, R J Donnelly
}

\begin{abstract}
An expandable metal stent inserted via a long term tracheostomy successfully relieved life threatening respiratory obstruction due to benign tracheal stenosis. Later the patient's tracheostomy suction catheter became stuck on the stent and dislodged it. The stent was removed electively, without damaging the trachea, with a rigid biopsy forceps.
\end{abstract}

(Thorax 1992;47:757-758)

Several reports have highlighted the value of expandable metal stents in the treatment of respiratory obstruction due to benign or malignant conditions affecting the trachea or main bronchi. ${ }^{1-3}$ Such stents are usually considered permanent as the fixation of the stent hooks to the mucosal wall is thought to make removal difficult. ${ }^{2}$ We describe a patient whose stent became dislodged two weeks after insertion and was therefore removed, without difficulty, via a rigid bronchoscope.

Cardiothoracic Centre, Broadgreen Hospital, Liverpool L14 3 PE

C R K Hind

R J Donnelly

Reprint requests to: Dr C R K Hind

Received 16 May 1991 Returned to authors 11 December 1991

Revised version received 16 January 1992

Accepted 28 January 1992

\section{Case report \\ A 51 year old housewife presented as an emergency with a three year history of increasing dyspnoea and stridor. Ten years previously she had received external radio- therapy to the neck for a postcricoid carci- noma. Three years later she developed laryn- geal stenosis secondary to the radiotherapy,}

and for the last seven years she had therefore required a tracheostomy tube. On admission she was cyanosed and breathless at rest.

On the day of her admission a flexible endoscope inserted via her tracheostomy site showed a benign looking stricture $3 \mathrm{~cm}$ below the tracheostomy site, which had reduced her tracheal lumen to about $2 \mathrm{~mm}$ in diameter. An attempt to dilate the tracheal stenosis with a 24 French gauge bougie caused bleeding at the stenosed site, and the patient became increasingly distressed. She was considered too ill to be transferred to the regional cardiothoracic centre and, in the absence of local facilities for rigid bronchoscopy, we decided to introduce a stent.

Two $2.5 \times 2 \mathrm{~cm}$ self expandable metal stents (Cook Inc, Bloomington, Indiana) were

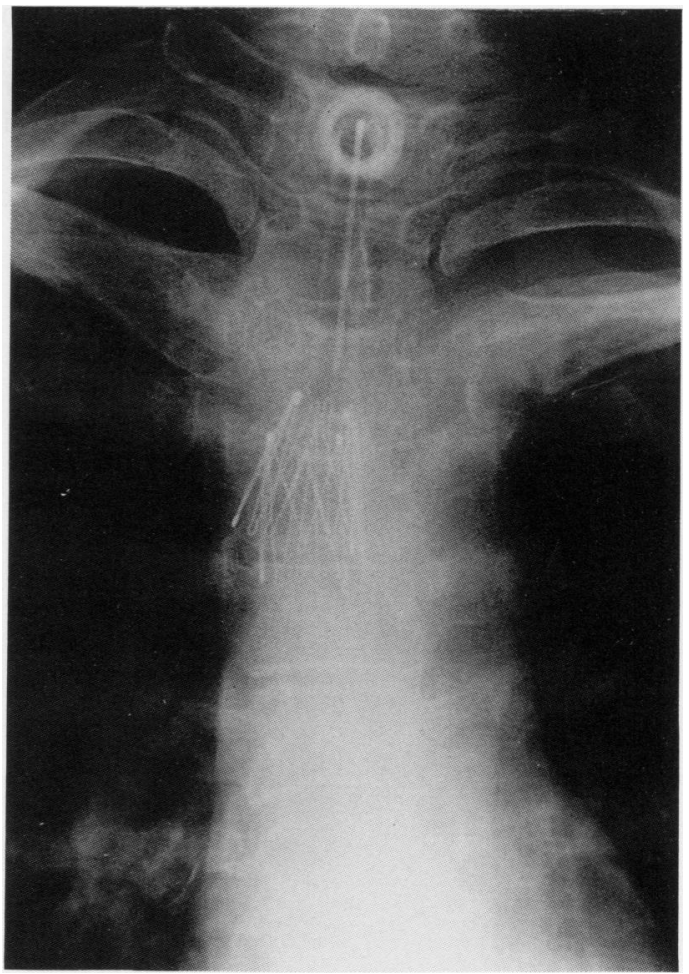

Figure 1 Detail of chest radiograph after disruption of the stent. 


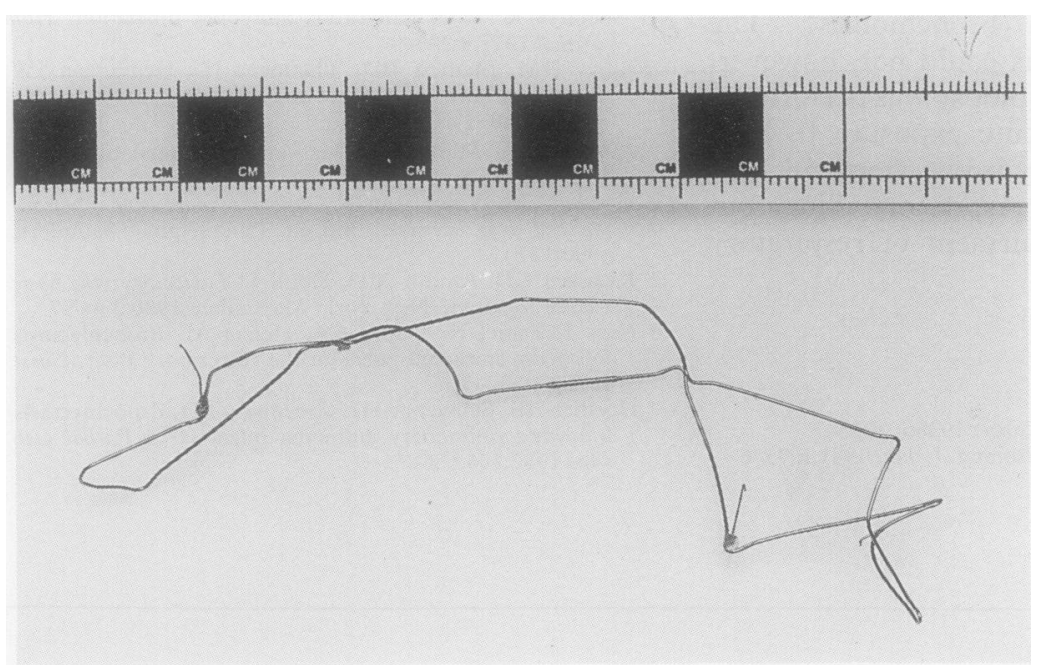

Figure 2 Disrupted expandable stent after removal from the trachea.

sequentially inserted across the stenosis by means of the delivery catheter system previously described ${ }^{23}$ and under direct vision with a fibreoptic bronchoscope.

The patient's breathing was immediately much improved, and she was comfortable and breathing room air within one hour. Over the next three days her exercise tolerance returned to normal, and sequential chest radiographs showed progressive opening of the stent (fig 1).

Over the next few days the patient continued her normal daily habit of tracheostomy suction, using a silicone tube with a fenestrated distal portion. During this procedure, 14 days after insertion of the stent, the suction catheter became caught and could not be removed despite vigorous traction by the patient. The entangled catheter was subsequently crushed and thereby released from the stent by the use of rigid biopsy forceps through a direct laryngoscope. It was evident, however, both endoscopically and radiologically, that both stents had been dislodged, though there was no respiratory embarrassment.

The patient was therefore transferred to this centre, where rigid bronchoscopy showed that the upper stent not only was disrupted but also now lay above the site of the previous stenosis of the trachea, which in turn was no longer narrowed. By the use of a rigid biopsy forceps the stent was therefore removed (fig 2), with no apparent endobronchial damage.

The patient remained well, though three months later she had to undergo elective endoscopic bougie dilatation because of restenosis at the site of her original tracheal narrowing. At that time the remaining stent was seen to be almost completely covered by bronchial mucosa.

\section{Discussion}

The reports of the use of self expanding metal stents in the treatment of tracheal or bronchial obstruction have emphasised that they should be considered only for permanent placement. ${ }^{2}$ Such stents have been used to relieve both benign and malignant major airway obstruction, with follow up periods of over 18 months in some cases. ${ }^{1-3}$ Experiments on dogs have shown that the stent becomes covered with respiratory mucosa after a few weeks, making removal impractical. ${ }^{3}$ Self expanding coronary artery stents suffer a similar fate. ${ }^{4}$

The in situ disruption of the self expanding stent that we report is, of course, a complication unique to patients who perform catheter suction of their tracheostomy site themselves. This case provides a warning of this potential danger, but also indicates that these stents can be removed within two weeks of their insertion.

1 Simonds AK, Irving JD, Clarke SW, Dick R. Use of expandable metal stents in the treatment of bronchial obstruction. Thorax 1989;44:680-1.

2 George PJM, Irving JD, Mantell BS, Rudd RM. Covered expandable metal stent for recurrent tracheal obstruction. Lancet 1990;i:582-4.

3 Wallace MJ, Charnsangavej C, Ogawa K, Carrasco $\mathrm{CH}$ Wright KC, McKenna R, et al. Tracheobronchial tree: expandable metallic stents used in experimental and clinical applications. Radiology 1986;158:309-12.

4 Serruys PW, Strauss BH, Beatt KJ, Bertrand ME, Puel J, Richards AF, et al. Angiographic follow-up after placement of a self-expanding coronary-artery stent. $N$ Engl $J$ Med 1991;324:13-7. 